\title{
Low preoperative regional cerebral oxygen saturation in hemodialysis patients
}

\author{
Shino Matsukawa, Miho Hamada and Toshiyuki Mizota* (10)
}

\begin{abstract}
Background: Regional cerebral oxygen saturation $\left(\mathrm{rSO}_{2}\right)$ monitoring by near-infrared spectroscopy provides valuable information regarding cerebral oxygen delivery, and it has been increasingly used in cardiovascular surgery. Although it has been shown that dialysis-dependent patients [hemodialysis (HD) patients] suffer from low cerebral perfusion, limited information is available on cerebral tissue oxygenation levels in HD patients.

Findings: In this retrospective study, the preoperative $\mathrm{rSO}_{2}$ values in $9 \mathrm{HD}$ patients undergoing coronary artery bypass graft surgery were compared with those in 40 non-HD patients. $\mathrm{HD}$ patients had lower preoperative $\mathrm{rSO}_{2}$ values than non-HD patients (median: 46 vs. 68\%, respectively, $P<0.001$ ). Despite adjusting for age, hemoglobin concentration, and left ventricular ejection fraction using multivariable linear regression, HD showed a strong association with low $\mathrm{rSO}_{2}$ (estimated coefficient: $-20.4, P<0.001$ ).
\end{abstract}

Conclusions: $\mathrm{HD}$ showed a strong association with low preoperative $\mathrm{rSO}_{2}$ values in patients undergoing coronary artery bypass graft surgery, even after adjusting for known factors that affect $\mathrm{rSO}_{2}$ values, including age, hemoglobin concentration, and cardiac systolic function. Further research is required to elucidate the mechanisms decreasing $\mathrm{rSO}_{2}$ values in $\mathrm{HD}$ patients.

Keywords: Hemodialysis, Regional cerebral oxygen saturation, Cardiac surgery

\section{Findings} Introduction

Regional cerebral oxygen saturation $\left(\mathrm{rSO}_{2}\right)$ monitoring by near-infrared spectroscopy has been increasingly used to assess the adequacy of cerebral oxygen delivery in patients undergoing cardiovascular surgery $[1,2]$. Previous studies have shown that $\mathrm{rSO}_{2}$, measured by near-infrared spectroscopy, is affected by several factors, including age, hemoglobin concentration, and cardiac function [3-7].

It has been shown that end-stage renal disease patients on hemodialysis (HD) suffer from low cerebral perfusion, which may contribute to cognitive deficits and high stroke prevalence observed in dialysis-dependent patients (HD patients) [8]. However, limited information is currently available on cerebral tissue oxygenation levels in HD patients.

Here, we hypothesized that the preoperative $\mathrm{rSO}_{2}$ values in $\mathrm{HD}$ patients undergoing cardiac surgery is lower than those in non-HD patients, reflecting low cerebral blood flow. The current study was designed to

\footnotetext{
* Correspondence: mizota@kuhp.kyoto-u.ac.jp

Department of Anesthesia, Kyoto University Hospital, 54

Shogoin-Kawahara-Cho, Sakyo-Ku, Kyoto 606-8507, Japan
}

compare the preoperative $\mathrm{rSO}_{2}$ values in $\mathrm{HD}$ patients and non-HD patients undergoing coronary artery bypass grafting (CABG).

\section{Methods}

Our study was approved by the ethics committee of Kyoto University (approval number: R0719), and the requirement for written informed consent was waived. We included adult ( $\geq 20$ years of age) patients who underwent isolated CABG at Kyoto University Hospital between January 1, 2012 and December 31, 2015. Patients who concurrently underwent cardiac valvular or aortic surgery were excluded. Patients without available $\mathrm{rSO}_{2}$ values taken before administration of oxygen or anesthetic drugs were also excluded.

Specific data from the electronic medical records of participants, including age, gender, body mass index, comorbidities, and preoperative examination findings, were retrospectively collected. Left ventricular ejection fraction (LVEF) was derived from preoperative transthoracic echocardiography records. For hemoglobin 
concentration values, the most recent value measured before the surgery was used.

Patients received no premedication. Upon entering the operating room, preoperative $\mathrm{rSO}_{2}$ and arterial oxygen saturation by pulse oximetry $\left(\mathrm{SpO}_{2}\right)$ were obtained before administration of oxygen or anesthetic drugs. $\mathrm{rSO}_{2}$ values were detected using the INVOS 5100 system (Somanetics, Troy, MI) with probes containing light sources, each providing two continuous wavelengths of near-infrared light $(730$ and $810 \mathrm{~nm})$ that reach a brain area corresponding to the junction between the anterior and middle cerebral artery vascularization territory. Two probes were attached to the right and the left sides of the forehead; the preoperative $\mathrm{rSO}_{2}$ values were defined as the mean of $\mathrm{rSO}_{2}$ values obtained from these two probes.

Data were analyzed using the statistical program $R$ (http://cran.r-project.org). Continuous data are presented as median (interquartile range), and categorical variables are expressed as a number (percentage). Differences between groups were compared using the Mann-Whitney $U$ test for continuous variables. For categorical variables, Pearson's chi-square or Fisher's exact tests were used as appropriate. Because it has been shown that $\mathrm{rSO}_{2}$ is affected by age, hemoglobin concentration, and cardiac function [3-7], we used multivariable linear regression analysis to assess the independent impact of $\mathrm{HD}$ on $\mathrm{rSO}_{2}$ values after adjustment for these factors. We constructed a linear regression model with $\mathrm{rSO}_{2}$ as a dependent variable and $\mathrm{HD}$ status, age, hemoglobin concentration, and LVEF as independent variables, and beta coefficients were calculated for all independent variables. All statistical tests were two-tailed, and the statistical significance was set at a $P$ value of $<0.05$.

\section{Results}

A total of 80 patients underwent isolated CABG during the study period. Of these, 31 patients were excluded because of the lack of $\mathrm{rSO}_{2}$ measurements before administration of oxygen or anesthetic drugs; the remaining 49 patients were included in the analysis. Among these 49 patients, 9 patients (18.4\%) received HD preoperatively. Duration of HD in HD patients ranged from 2 to 14 years; 4 patients (44.4\%) underwent HD for $\geq 10$ years. Patient characteristics stratified by HD status are presented in Table 1 . HD patients had significantly higher prevalence of diabetes mellitus and arteriosclerosis obliterans and significantly lower hemoglobin concentrations than non-HD patients. Although it did not reach statistical significance, LVEF in HD patients tended to be lower than that in non-HD patients.

Distributions of preoperative $\mathrm{rSO}_{2}$ and $\mathrm{SpO}_{2}$ values stratified by HD status are shown in Fig. 1. HD patients had significantly lower $\mathrm{rSO}_{2}$ values than non-HD patients $[46 \%(43-50 \%)$ vs. $68 \%(64-73 \%), P<0.001$; Fig. 1a]. No patients had an $\mathrm{rSO}_{2}$ value of $\leq 50 \%$ in the non-HD group, whereas 7 out of $9 \mathrm{HD}$ patients (77.8\%) had an $\mathrm{rSO}_{2}$ value of $\leq 50 \%$. $\mathrm{SpO}_{2}$ values of study participants ranged from $94-100 \%$ and were comparable between groups $(P=0.625$; Fig. $1 b)$.

Multivariable linear regression analysis was performed to assess the impact of $\mathrm{HD}$ on preoperative $\mathrm{rSO}_{2}$ values after adjustment for age, hemoglobin concentration, and LVEF, which have been shown to affect $\mathrm{rSO}_{2}$ in previous studies [3-7]. HD maintained a strong association with low $\mathrm{rSO}_{2}$, even after adjusting for age, hemoglobin concentration, and LVEF. The estimated coefficient for HD in the multivariable model was -20.4 (95\% confidence interval: -26.3 to -14.4 ) (Table 2).

\section{Discussion}

This study demonstrated that HD patients had significantly lower preoperative $\mathrm{rSO}_{2}$ values, even after adjusting for known factors that affect $\mathrm{rSO}_{2}$, including age, hemoglobin concentration, and LVEF.

Several reports have suggested that patients undergoing $\mathrm{HD}$ have low $\mathrm{rSO}_{2}$ values, reflecting low cerebral perfusion [9, 10]; however, they did not assess cardiac

Table 1 Patient characteristics stratified by HD

\begin{tabular}{llll}
\hline & $\begin{array}{l}\text { Non-HD patients } \\
(n=40)\end{array}$ & $\begin{array}{l}\text { HD patients } \\
(n=9)\end{array}$ & $P$ value \\
\hline Age (years) & $73(64-78)$ & $73(69-77)$ & 0.846 \\
Female gender & $7(17.5 \%)$ & $2(22.2 \%)$ & 0.741 \\
Body mass index $\left(\mathrm{kg} / \mathrm{m}^{2}\right)$ & $23.4(21.7-25.3)$ & $22.2(19.4-24.2)$ & 0.245 \\
Hypertension & $30(75.0 \%)$ & $7(77.8 \%)$ & 0.861 \\
Diabetes mellitus & $13(32.5 \%)$ & $9(100.0 \%)$ & $<(44.4 \%)$ \\
ASO & $1(2.5 \%)$ & $10.1(9.7-11.8)$ & $<0.001$ \\
Hemoglobin concentration $(\mathrm{g} / \mathrm{dL})$ & $12.7(11.9-14.1)$ & $50.0(29.9-73.9)$ & 0.001 \\
LVEF $(\%)^{a}$ & $66.0(55.3-72.0)$ & 0.398 \\
\hline
\end{tabular}

$\mathrm{HD}$ hemodialysis, $\mathrm{ASO}$ arteriosclerosis obliterans, $\mathrm{LVEF}$ left ventricular ejection fraction, $\mathrm{rSO}_{2}$ regional cerebral oxygen saturation

a LVEF was missing in one non-HD patient 

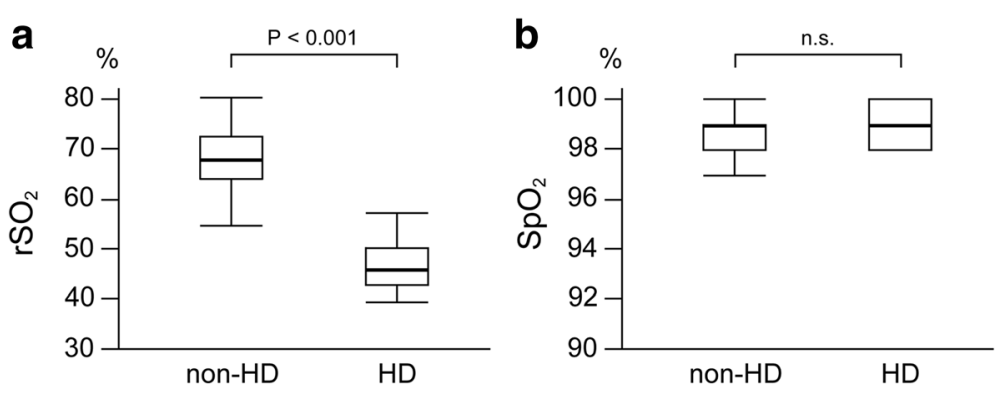

Fig. 1 Box plots of preoperative $\mathrm{rSO}_{2}(\mathbf{a})$ and $\mathrm{SpO}_{2}$ (b) values stratified by $\mathrm{HD}$. Horizontal bold lines represent median values. $\mathrm{rSO}_{2}$ regional cerebral oxygen saturation, $\mathrm{SpO}_{2}$ arterial oxygen saturation of pulse oximetry, $\mathrm{HD}$ hemodialysis, n.s. not significant

function, which is known to affect $\mathrm{rSO}_{2}$ values [7]. In our study, we were able to compare $\mathrm{rSO}_{2}$ values in $\mathrm{HD}$ and non-HD patients after adjusting for LVEF because most patients underwent preoperative transthoracic echocardiography. Although HD patients had significantly lower hemoglobin concentrations than non-HD patients, and LVEF in HD patients tended to be lower, the estimated coefficient for $\mathrm{HD}$ in the multivariable linear regression analysis, adjusting for age, hemoglobin concentration, and LVEF, was -20.4. This means that HD patients had $20.4 \%$ lower $\mathrm{rSO}_{2}$ values than non-HD patients after adjusting for these factors, indicating that low $\mathrm{rSO}_{2}$ values in $\mathrm{HD}$ patients are, at least in part, because of factors other than age, anemia, or cardiac systolic function. Although it is not possible to determine the specific cause of low $\mathrm{rSO}_{2}$ values in $\mathrm{HD}$ patients in our study, possible explanations are as follows: (1) metabolic acidosis frequently seen in HD patients decreases affinity between hemoglobin and oxygen [11] and decreases microcirculatory oxygen saturation. (2) The acute intravascular volume loss and fluid shifts that occur during dialysis induce cerebral edema and decrease intracerebral blood pressure, blood velocity, and cerebral perfusion [12]. (3) Cerebral atrophy seen in HD patients [13] might increase the thickness of the cerebrospinal fluid layer, which decreases the intensity of near-infrared light that the detector can receive, thereby, decreasing $\mathrm{rSO}_{2}$ values [5]. Further research is

Table 2 Multivariable linear regression analysis for the association of $\mathrm{HD}$ and $\mathrm{rSO}_{2}$, adjusting for age, hemoglobin concentration, and LVEF

\begin{tabular}{lll}
\hline & Beta (95\% confidence interval) & $P$ value \\
\hline Intercept & $60.9(39.0$ to 82.8$)$ & \\
HD & $-20.4(-26.3$ to -14.4$)$ & $<0.001$ \\
age & $-0.03(-0.22$ to 0.16$)$ & 0.753 \\
Hemoglobin concentration & $0.38(-0.78$ to 1.55$)$ & 0.510 \\
LVEF $^{a}$ & $0.08(-0.05$ to 0.20$)$ & 0.236 \\
\hline
\end{tabular}

$\mathrm{HD}$ hemodialysis, $\mathrm{rSO}_{2}$ regional cerebral oxygen saturation, $L V E F$ left ventricular ejection fraction

${ }^{a}$ One non-HD patient with missing LVEF data was excluded from this analysis required to elucidate the mechanisms by which the $\mathrm{rSO}_{2}$ values are decreased in HD patients.

It is important to determine adequate target values of $\mathrm{rSO}_{2}$ to guide intraoperative management in $\mathrm{HD}$ patients. $\mathrm{rSO}_{2}$ monitoring may be used to guide hemodynamics and $\mathrm{CPB}$ management during cardiac surgery by adjusting therapy based on relative changes from the preoperative baseline (i.e., to maintain relative $\mathrm{rSO}_{2}>80 \%$ of baseline) [14]. However, this concept might allow too low $\mathrm{rSO}_{2}$ values and be harmful for majority of $\mathrm{HD}$ patients, who frequently have abnormally low baseline $\mathrm{rSO}_{2}$ values. Future research should be conducted to establish the appropriate target value of $\mathrm{rSO}_{2}$ in $\mathrm{HD}$ patients.

This study had certain limitations, primarily based on its retrospective design. We used only preoperative LVEF to evaluate cardiac function because data on diastolic function or cardiac output were not available in most patients. In addition, we could not adjust for the influence of some factors, which are suggested to be related to $\mathrm{rSO}_{2}$, including partial pressure of carbon dioxide in arterial blood, central venous pressure, skull thickness, and area of cerebrospinal fluid layer $[4,5]$. The number of patients was small; however, it was still sufficient to support our hypothesis.

\section{Conclusions}

In conclusion, this study demonstrated that HD showed strong associations with low preoperative $\mathrm{rSO}_{2}$ values in patients undergoing CABG, even after adjusting for known factors that affect $\mathrm{rSO}_{2}$ values, including age, hemoglobin concentration, and cardiac systolic function.

\section{Abbreviations}

CABG: Coronary artery bypass grafting; HD: Hemodialysis; LVEF: Left ventricular ejection fraction; $\mathrm{rSO}_{2}$ : Regional cerebral oxygen saturation; $\mathrm{SpO}_{2}$ : Arterial oxygen saturation by pulse oximetry

\section{Acknowledgements}

The authors would like to thank Enago (www.enago.jp) for the English language review.

\section{Funding}

This work was in part supported by JSPS KAKENHI (grant number 16K20092; $\mathrm{TM}$, principle investigator). 


\section{Authors' contributions}

SM conceptualized and designed the study, collected the data, performed the statistical analysis, and drafted the first version of the manuscript. MH helped draft the manuscript. TM helped with the statistical analysis and critically revised the manuscript. All authors read and approved the manuscript.

\section{Competing interests}

The authors declare that they have no competing interests.

\section{Publisher's Note}

Springer Nature remains neutral with regard to jurisdictional claims in published maps and institutional affiliations.

Received: 2 February 2017 Accepted: 28 March 2017

Published online: 08 April 2017

\section{References}

1. Fischer GW. Recent advances in application of cerebral oximetry in adult cardiovascular surgery. Semin Cardiothorac Vasc Anesth. 2008;12:60-9.

2. Murkin JM, Arango M. Near-infrared spectroscopy as an index of brain and tissue oxygenation. Br J Anaesth. 2009:103:13-13.

3. Kishi K, Kawaguchi M, Yoshitani K, Nagahata T, Furuya H. Influence of patient variables and sensor location on regional cerebral oxygen saturation measured by INVOS 4100 near-infrared spectrophotometers. J Neurosurg Anesthesiol. 2003:15:302-6.

4. Moritz S, Rochon J, Völkel S, Hilker M, Hobbhahn J, Graf BM, Arlt M. Determinants of cerebral oximetry in patients undergoing off-pump coronary artery bypass grafting: an observational study. Eur J Anaesthesiol. 2010;27:542-9.

5. Yoshitani K, Kawaguchi M, Miura N, Okuno T, Kanoda T, Ohnishi Y, Kuro M. Effects of hemoglobin concentration, skull thickness, and the area of the cerebrospinal fluid layer on near-infrared spectroscopy measurements. Anesthesiology. 2007;106:458-62.

6. Papadopoulos G, Karanikolas M, Liarmakopoulou A, Berris A. Baseline cerebral oximetry values in elderly patients with hip fractures: a prospective observational study. Injury. 2011:42:1328-32.

7. Paquet C, Deschamps A, Denault AY, Couture P, Carrier M, Babin D, Levesque S, Piquette D, Lambert J, Tardif JC. Baseline regional cerebral oxygen saturation correlates with left ventricular systolic and diastolic function. J Cardiothorac Vasc Anesth. 2008;22:840-6.

8. Prohovnik I, Post J, Uribarri J, Lee H, Sandu O, Langhoff E. Cerebrovascular effects of hemodialysis in chronic kidney disease. J Cereb Blood Flow Metab. 2007:27:1861-9.

9. Hoshino T, Ookawara S, Goto S, Miyazawa H, Ito K, Ueda Y, Kaku Y, Hirai K, Nabata A, Mori H, Yoshida I, Tabei K. Evaluation of cerebral oxygenation in patients undergoing long-term hemodialysis. Nephron Clin Pract. 2014;126:57-61.

10. Papadopoulos G, Dounousi E, Papathanasiou A, Papathanakos G, Tzimas P. Cerebral oximetry values in dialyzed surgical patients: a comparison between hemodialysis and peritoneal dialysis. Ren Fail. 2013;35:855-9.

11. Opdahl H, Strømme TA, Jørgensen L, Bajelan L, Heier HE. The acidosisinduced right shift of the $\mathrm{HbO}_{2}$ dissociation curve is maintained during erythrocyte storage. Scand J Clin Lab Invest. 2011;71:314-21.

12. Murray AM, Tupper DE, Knopman DS, Gilbertson DT, Pederson SL, Li S, Smith GE, Hochhalter AK, Collins AJ, Kane RL. Cognitive impairment in hemodialysis patients is common. Neurology. 2006;67:216-23.

13. Drew DA, Bhadelia R, Tighiouart H, Novak V, Scott TM, Lou KV, Shaffi K, Weiner DE, Sarnak MJ. Anatomic brain disease in hemodialysis patients: a cross-sectional study. Am J Kidney Dis. 2013;61:271-8.

14. Denault A, Deschamps A, Murkin JM. A proposed algorithm for the intraoperative use of cerebral near-infrared spectroscopy. Semin Cardiothorac Vasc Anesth. 2007:11:274-81.

\section{Submit your manuscript to a SpringerOpen ${ }^{\circ}$ journal and benefit from:}

- Convenient online submission

- Rigorous peer review

- Immediate publication on acceptance

- Open access: articles freely available online

- High visibility within the field

- Retaining the copyright to your article

Submit your next manuscript at $\boldsymbol{s p r i n g e r o p e n . c o m ~}$ 